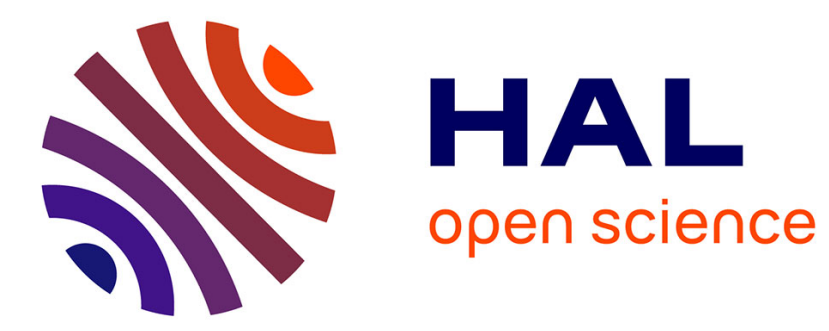

\title{
Tailoring GaAs teraHertz radiative properties with surface phonons polaritons
}

Simon Vassant, François Marquier, Jean-Jacques Greffet, Fabrice Pardo, Jean-Luc Pelouard

\section{- To cite this version:}

Simon Vassant, François Marquier, Jean-Jacques Greffet, Fabrice Pardo, Jean-Luc Pelouard. Tailoring GaAs teraHertz radiative properties with surface phonons polaritons. Applied Physics Letters, 2010, 97 (16), pp.161101. 10.1063/1.3497645 . hal-00574372

\section{HAL Id: hal-00574372}

https://hal-iogs.archives-ouvertes.fr/hal-00574372

Submitted on 3 Dec 2015

HAL is a multi-disciplinary open access archive for the deposit and dissemination of scientific research documents, whether they are published or not. The documents may come from teaching and research institutions in France or abroad, or from public or private research centers.
L'archive ouverte pluridisciplinaire HAL, est destinée au dépôt et à la diffusion de documents scientifiques de niveau recherche, publiés ou non, émanant des établissements d'enseignement et de recherche français ou étrangers, des laboratoires publics ou privés. 


\section{A|P|Applied Physics Letters}

\section{Tailoring GaAs terahertz radiative properties with surface phonons polaritons}

S. Vassant, F. Marquier, J. J. Greffet, F. Pardo, and J. L. Pelouard

Citation: Applied Physics Letters 97, 161101 (2010); doi: 10.1063/1.3497645

View online: http://dx.doi.org/10.1063/1.3497645

View Table of Contents: http://scitation.aip.org/content/aip/journal/apl/97/16?ver=pdfcov

Published by the AIP Publishing

\section{Articles you may be interested in}

Engineering absorption and blackbody radiation in the far-infrared with surface phonon polaritons on gallium phosphide

Appl. Phys. Lett. 104, 131105 (2014); 10.1063/1.4870255

Toward stimulated interaction of surface phonon polaritons

J. Appl. Phys. 114, 233508 (2013); 10.1063/1.4851717

Excitation of terahertz plasmon-polariton in a grating coupled two-dimensional electron gas with a Fabry-

Pérot cavity

Appl. Phys. Lett. 102, 253106 (2013); 10.1063/1.4812359

Subwavelength focusing of terahertz/far-infrared radiation via phonon-polariton resonance in polar salt antenna structures

J. Appl. Phys. 106, 044310 (2009); 10.1063/1.3200955

Surface and interface phonon-polaritons in bilayer systems of polar ternary mixed crystals

J. Appl. Phys. 104, 033545 (2008); 10.1063/1.2965190

\section{AIP $\mid$ APL Photonics}

APL Photonics is pleased to announce Benjamin Eggleton as its Editor-in-Chief

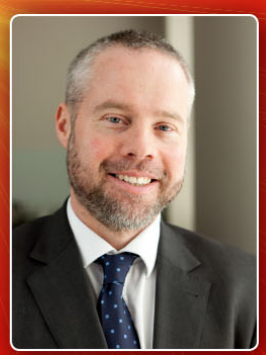




\title{
Tailoring GaAs terahertz radiative properties with surface phonons polaritons
}

\author{
S. Vassant, ${ }^{1, a)}$ F. Marquier, ${ }^{1}$ J. J. Greffet, ${ }^{1}$ F. Pardo, ${ }^{2}$ and J. L. Pelouard ${ }^{2}$ \\ ${ }^{1}$ Laboratoire Charles Fabry, Institut d'Optique, CNRS, Université Paris-Sud, Campus Polytechnique, \\ RD 128, 91127 Palaiseau Cedex, France \\ ${ }^{2}$ Laboratoire de Photonique et Nanostructure, CNRS-UPR20, Route de Nozay, 91460 Marcoussis, France
}

(Received 25 June 2010; accepted 15 September 2010; published online 18 October 2010)

\begin{abstract}
Absorption of visible and infrared radiation by gratings due to the resonant excitation of surface waves is a well-known phenomenon. In this paper, we study the resonant absorption of terahertz $(\mathrm{THz})$ radiation due to the excitation of surface phonon polaritons on a grating ruled on a GaAs substrate. We report the design and fabrication of such a grating. Reflectivity measurements clearly show the excitation of surface phonon polariton. Numerical simulations indicate that the radiative properties depend critically on the surface profile. We finally discuss potential applications to $\mathrm{THz}$ thermal emission. () 2010 American Institute of Physics. [doi:10.1063/1.3497645]
\end{abstract}

It has been known since the pioneering work of Maystre and Hutley ${ }^{1}$ that metals can be efficient absorbers in the visible spectrum when a properly designed grating is ruled on the surface so that surface plasmon polaritons can be excited resonantly. This has paved the way to a large number of light sources in which emission is mediated by surface plasmons. ${ }^{2,3}$ Similar effects have been reported in the infrared taking advantage of the excitation of surface phonon polaritons (SPhP). The group of Vinogradov has observed IR thermal emission using prisms to couple the surface waves. ${ }^{4}$ Total absorption by a grating on $\mathrm{SiC}$ and coherent thermal emission also due to SPhP was later reported in the mid $\mathrm{IR}^{5}$ The similarity of SPhP and surface plasmons has been investigated in the near-field in different experiments by $\mathrm{R}$. Hillenbrand. ${ }^{6,7}$

Several groups have shown the potential of surface waves for designing efficient IR thermal emitters using gratings, ${ }^{8,9}$ multilayers systems, ${ }^{10-12}$ resonant microstructures. ${ }^{13-16}$ These solutions open new avenues for the design of "easy-to-fabricate" sources with an emission spectrum centered on a range of interest. In this paper we address the issue of terahertz $(\mathrm{THz})$ emission. It is wellknown that there are very few sources ${ }^{17,18}$ and detectors ${ }^{19}$ available in this part of the electromagnetic spectrum. In addition, these devices are often limited by losses, mainly due to optical phonons as electron relaxation through phonon emission is much faster than other processes. Yet, one can take advantage of the optical phonons for direct emission of radiation through the radiative leakage of SPhP. In this work, we show that a grating ruled on GaAs can be designed in order to efficiently absorb incident light. Due to Kirchhoff's law, ${ }^{20}$ this entails a large emissivity. We compare experiments and theory and show a design producing an emissivity close to 1 for a specific wavelength and a broad range of angles.

To describe the dielectric constant $\epsilon$ of GaAs, we use a classical Lorentzian model with parameters from Palik $^{21}\left(\omega_{\mathrm{LO}}=292.1 \mathrm{~cm}^{-1}, \omega_{\mathrm{TO}}=267.98 \mathrm{~cm}^{-1}, \gamma=2.4 \mathrm{~cm}^{-1}\right.$, and $\left.\epsilon_{\infty}=11\right)$. The dielectric constant is given by Eq. (1).

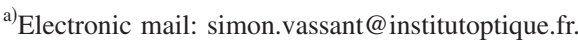

$$
\epsilon=\epsilon_{\infty}\left(1+\frac{\omega_{\mathrm{LO}}^{2}-\omega_{\mathrm{TO}}^{2}}{\omega_{\mathrm{TO}}^{2}-\omega^{2}-i \omega \gamma}\right),
$$

with $\omega_{\mathrm{TO}}$ and $\omega_{\mathrm{LO}}$, respectively, the transverse and longitudinal optical phonon frequency and $\gamma$ a damping term. The dispersion relation of the surface phonon wave for a flat surface is derived from Maxwell's equations ${ }^{22}$

$$
k_{\mathrm{SPhP}}=\frac{\omega}{c} \sqrt{\frac{\epsilon}{\epsilon+1}} .
$$

Surface waves can gain momentum from a grating ruled on the surface, in multiple of $2 \pi / \Lambda$ where $\Lambda$ is the grating period. This phenomenon enables coupling of propagating light to SPhP which results in dips in the reflectivity spectrum of the grating. The geometric configuration for simulations and experiment is shown in Fig. 1(a).

GaAs gratings have been fabricated at the LPN from a semi-insulating, [100] oriented wafer with epitaxial surface quality. The grating has been ruled using standard optical lithography techniques and Ti35ES resist (Microchemicals). This resist was an efficient mask for subsequent reactive ion etching with inductively coupled plasma (RIE-ICP). The

(a)

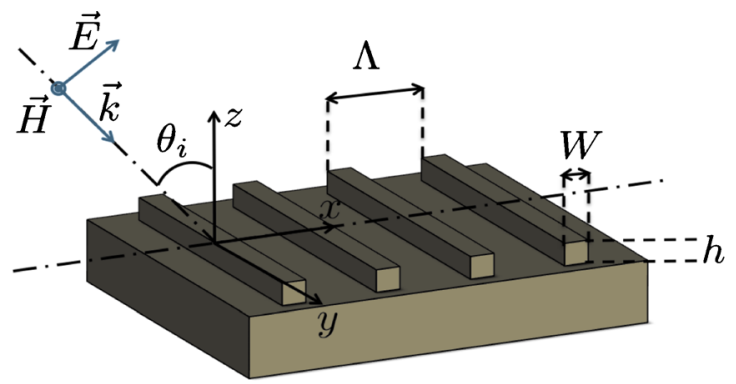

(b)
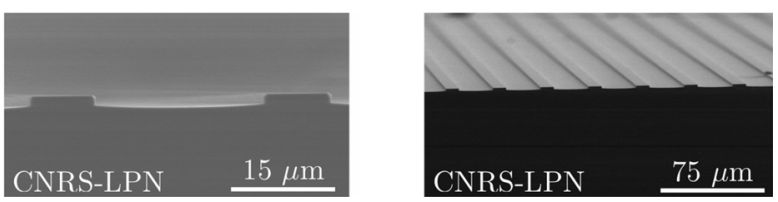

FIG. 1. (Color online) (a) Scheme of the grating geometry. The incident field is represented for TM polarization. (b) SEM pictures of the GaAs grating. 


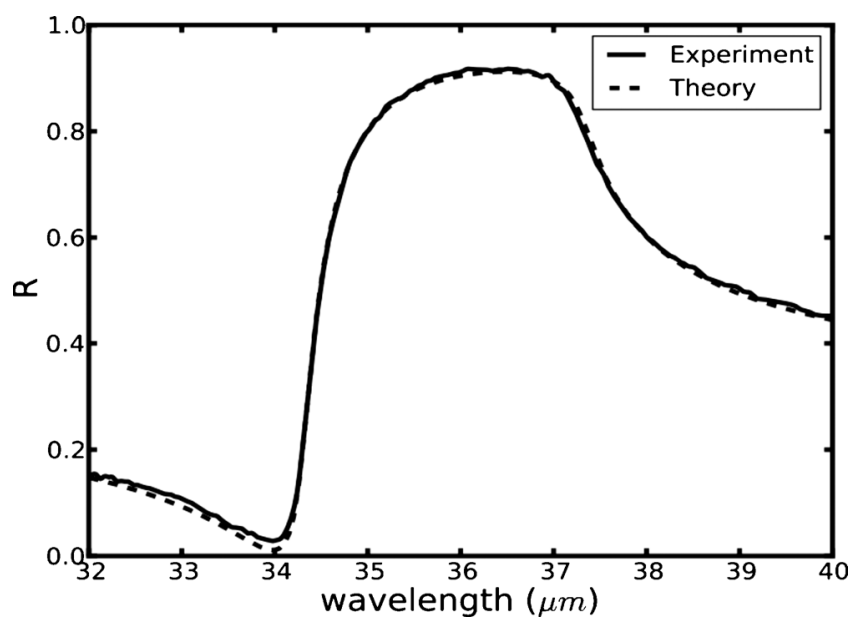

FIG. 2. Reflectivity of a GaAs flat surface $\left(\theta_{i}=15^{\circ}\right)$.

GaAs substrate was etched with gas concentration of $15 / 5 / 20$ $\mathrm{SCCM}$ for, respectively, $\mathrm{BCl}_{3} / \mathrm{Cl}_{2} / \mathrm{Ar}$, an ICP power of 600 $\mathrm{W}$, rf power of $50 \mathrm{~W}$, during $720 \mathrm{~s}$ at a temperature of $30{ }^{\circ} \mathrm{C}$. The thickness of the grating $h$ was measured with a mechanical profilometer and yielded $2.8 \mu \mathrm{m}$, with a good uniformity on the whole 5 by $5 \mathrm{~mm}$ grating. The period $\Lambda$ was set to $35 \mu \mathrm{m}$, and the filling factor $(F=W / \Lambda)$ is measured to be around 0.3 .

Reflectivity spectra, have been taken with a far-infrared Fourier transform spectrometer (Vertex 70, Bruker Optics), purged with dry air, and equipped with a A513/Q variable angle reflection set-up. The incident beam was polarized with a THz polarizer (Tydex). The orientation of the grating with respect to the plane of incidence was controlled with a visible laser and the diffracted orders, ensuring grooves perpendicular to the plane of incidence [Fig. 1(a)]. This has allowed us to measure the reflectivity of the grating in the specular direction for different angle of incidence $\left(\theta_{i}\right)$ between $15^{\circ}$ and $75^{\circ}$.

We present now experimental results and compare them with numerical simulations using a rigorous coupled wave analysis (RCWA) technique. ${ }^{23}$ First, measurement on the flat area of the GaAs sample are made to control the validity of the parameters used for the dielectric constant.

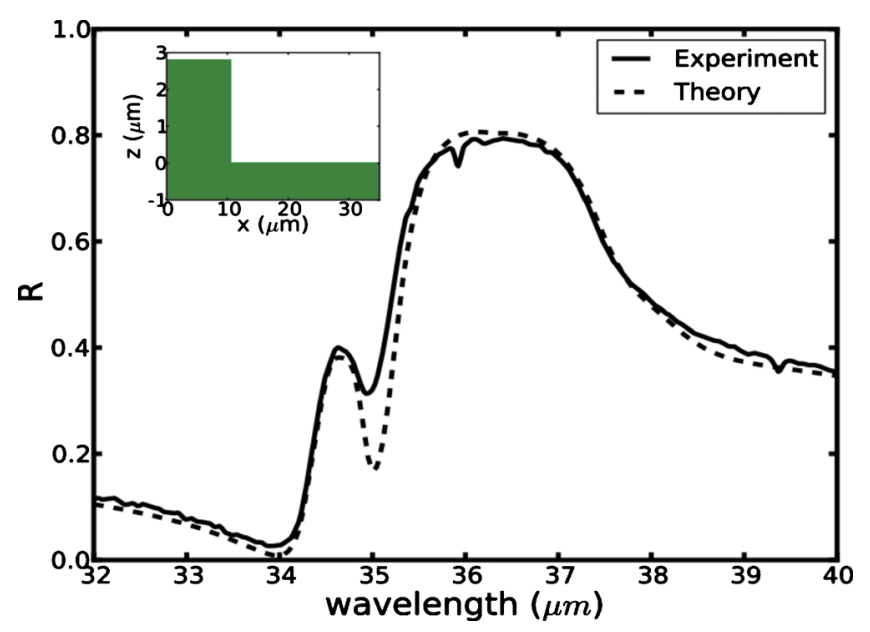

FIG. 3. (Color online) Reflectivity of a GaAs grating and simulated geometry in the inset $\left(\theta_{i}=15^{\circ}\right)$.

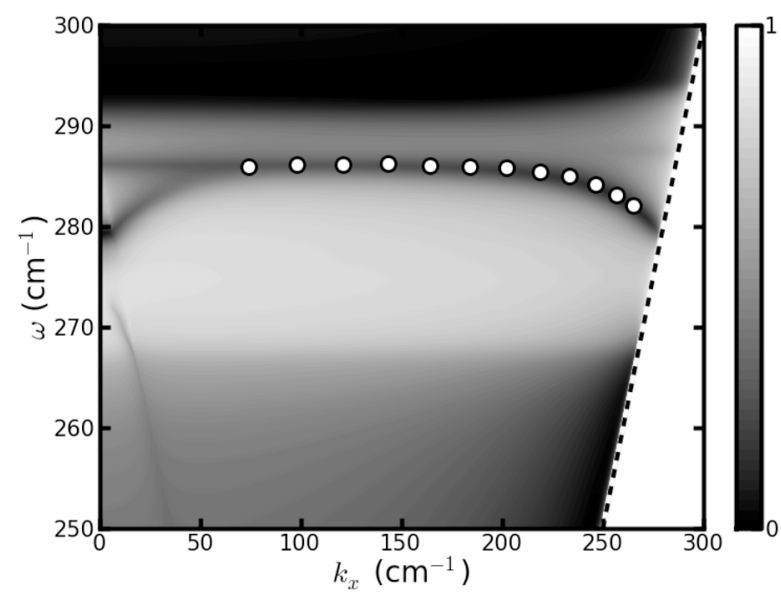

FIG. 4. Reflectivity map calculated for a GaAs grating of $35 \mu \mathrm{m}$ period with a filling factor of 0.3 and a height of $2.8 \mu \mathrm{m}$. White is for high reflectivity, while black is for low reflectivity. White filled circles indicate the position of measured reflectivity dips.

When using Palik values, the computed reflectivity shows a slight difference with measurement. A least square $\mathrm{fit}^{24}$ with $\omega_{\mathrm{LO}}$ as single free parameter gives us a wavenumber of $291.762 \pm 0.007 \mathrm{~cm}^{-1}$. This value gives a very good agreement between theoretical and measured spectrum, as shown in Fig. 2, and will be used for the other simulations. This value is close to the Palik value of $292.1 \mathrm{~cm}^{-1}$, and to the value obtained from oblique reflectivity measurements by Lockwood et $a .^{25}$ of $292.01 \mathrm{~cm}^{-1}$. This small difference (less than $0.05 \mathrm{meV}$ ) may be due to temperature effect, as we do not control it.

Measurement of the grating reflectivity (Fig. 3) shows a clear dip only in TM polarization at $34.9 \mu \mathrm{m}$. The other small features at 36 and $39.5 \mu \mathrm{m}$ are clearly identified as rotational transitions of water molecules. The theory shows a good agreement on the SPhP dip frequency but not on the amplitude.

From RCWA calculation, we calculate the reflectivity map of the SPhP (Fig. 4), over which we plot the position of the dips, measured between $15^{\circ}$ and $75^{\circ}$, every $5^{\circ}$ for $\theta_{i}$. The dip frequency angular dependence agrees very well with the theoretical dispersion relation (Fig. 4). The reflectivity dips can, therefore, be attributed to the excitation of SPhP.

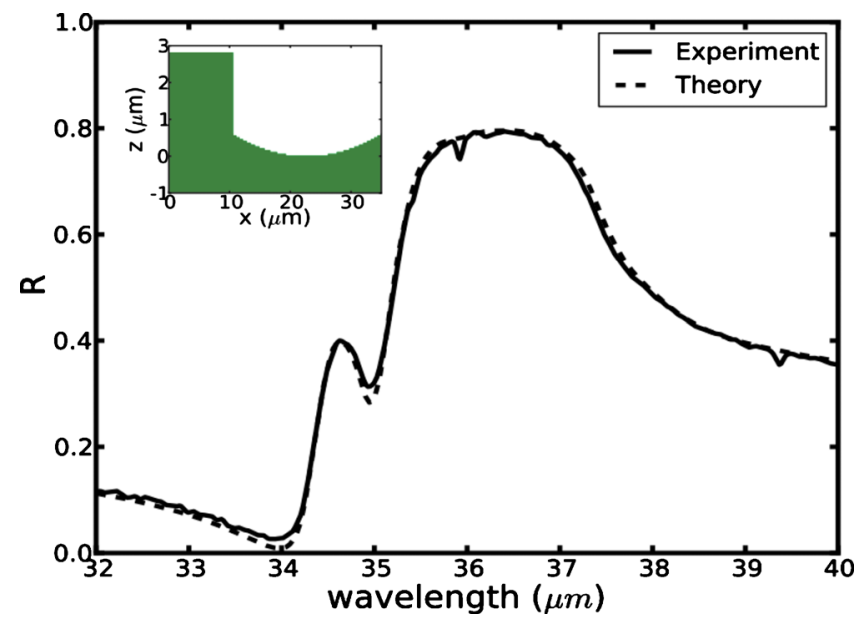

FIG. 5. (Color online) Reflectivity of a GaAs grating and simulated geometry in the inset $\left(\theta_{i}=15^{\circ}\right)$. 


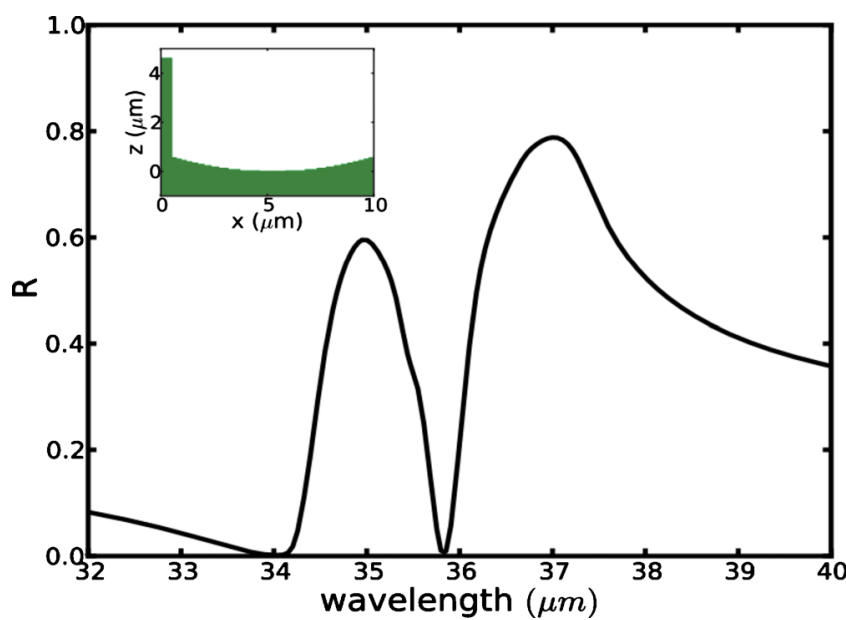

FIG. 6. (Color online) Reflectivity of an optimized GaAs grating and simulated geometry in the inset $\left(\theta_{i}=45^{\circ}\right)$.

The difference of reflectivity dip amplitude between theory and experiment can be explained by a careful look at the sample geometry. We cleaved the sample perpendicular to the grooves and side observation showed that the bottom of the grating is not flat but has a slight curvature [see Fig. 1(b)]. This bottom curvature, often seen in RIE-ICP etching, was then taken into account in the simulation. The theoretical and experimental spectrums are shown in Fig. 5 with the geometry used for the simulation in the inset. Direct calculation with a bottom curvature of $600 \mathrm{~nm}$ [taken from scanning electron microscope (SEM) measurements] shows a good agreement with data.

We now show that a different design can produce a reflectivity dip close to zero, even if the grating has such bottom curvature. Figure 6 displays the reflectivity for a grating $(\Lambda=10 \mu \mathrm{m}, h=4 \mu \mathrm{m}$, and $F=0.05)$ that goes to zero near $36 \mu \mathrm{m}$. Although the aspect ratio is large, it is within the reach of current technology. It is thus possible to reach total absorption which implies that this grating is a good candidate for the design of a $\mathrm{THz}$ emitter around $35.5 \mu \mathrm{m}$.

In summary, we have shown that surface phonons polaritons can be used in the $\mathrm{THz}$ range to control reflectivity and emissivity of GaAs surface. This study is a first step toward the use of surface phonons polaritons for $\mathrm{THz}$ sources.
This work has been supported by ANR (ANR-07NANO-043) contract LAPSUS and by the region Ile de France through a C' Nano Idf project. We wish to thank N. Bardou, C. Dupuis, L. Ferlazzo, and E. Cambril for their useful help in the clean room.

${ }^{1}$ M. C. Hutley and D. Maystre, Opt. Commun. 19, 431 (1976).

${ }^{2}$ S. Wedge, J. A. E. Wasey, W. L. Barnes, and I. Sage, Appl. Phys. Lett. 85, 182 (2004).

${ }^{3}$ J. A. Schuller, E. S. Barnard, W. Cai, Y. Chul Jun, J. S. White, and M. 1. Brongersma, Nature Mater. 9, 193 (2010).

${ }^{4}$ E. A. Vinogradov, G. N. Zhizhin, and V. I. Yudson, in Surface Polaritons, edited by V. M. Agranovich and D. L. Mills (North-Holland, Amsterdam, 1982), Vol. 145.

${ }^{5}$ J. J. Greffet, R. Carminati, K. Joulain, J.-P. Mulet, S. Mainguy, and Y. Chen, Nature (London) 416, 61 (2002).

${ }^{6} \mathrm{~N}$. Ocelic and R. Hillenbrand, Nature Mater. 3, 606 (2004).

${ }^{7}$ R. Hillenbrand, T. Taubner, and F. Keilmann, Nature (London) 418, 159 (2002).

${ }^{8}$ F. Marquier, K. Joulain, J. Mulet, R. Carminati, and Y. Chen, Phys. Rev. B 69, 155412 (2004).

${ }^{9}$ N. Dahan, A. Niv, G. Biener, Y. Gorodetski, V. Kleiner, and E. Hasman, Phys. Rev. B 76, 045427 (2007).

${ }^{10}$ B. J. Lee, Y. B. Chen, and Z. M. Zhang, Opt. Lett. 33, 204 (2008).

${ }^{11}$ O. G. Kollyukh, A. Liptuga, V. Morozhenko, and V. Pipa, Opt. Commun. 225, 349 (2003).

${ }^{12}$ P. Ben-Abdallah, J. Opt. Soc. Am. A 21, 1368 (2004).

${ }^{13}$ I. Puscasu and W. L. Schaich, Appl. Phys. Lett. 92, 233102 (2008).

${ }^{14}$ J. A. Schuller, T. Taubner, and M. L. Brongersma, Nat. Photonics 3, 658 (2009).

${ }^{15}$ Y. Y. Au, Phys. Rev. B 78, 085402 (2008).

${ }^{16}$ H. T. Miyazaki, K. Ikeda, T. Kasaya, K. Yamamoto, Y. Inoue, K. Fujimura, T. Kanakugi, M. Okada, K. Hatade, and S. Kitagawa, Appl. Phys. Lett. 92, 141114 (2008).

${ }^{17}$ P. Uhd Jepsen, R. H. Jacobsen, and S. R. Keiding, J. Opt. Soc. Am. B 13, 2424 (1996).

${ }^{18}$ C. Sirtori, C. Gmachl, F. Capasso, J. Faist, D. L. Sivco, A. L. Hutchinson, and A. Y. Cho, Opt. Lett. 23, 1366 (1998).

${ }^{19}$ Y. Cai, J. Lopata, L. Wynn, J. Pfeiffer, J. B. Stark, Q. Wu, X. C. Zhang, and J. F. Federici, Appl. Phys. Lett. 73, 444 (1998).

${ }^{20}$ J. J. Greffet and M. Nieto-Vesperinas, J. Opt. Soc. Am. A 15, 2735 (1998).

${ }^{21}$ E. D. Palik, Handbook of Optical Constants of Solids (Academic, New York, 1985)

${ }^{22}$ H. Raether, Surface Plasmons (Springer, New York, 1988).

${ }^{23}$ L. Li, J. Opt. Soc. Am. A 14, 2758 (1997).

${ }^{24}$ P. T. Boggs, R. H. Byrd, J. R. Rogers, and R. B. Schnabel, User's Reference Guide for ODRPACK version 2.01 Software for Weighted Orthogonal Distance Regression (National Inst. of Standards and Technology, Gaithersburg, MD, 1992).

${ }^{25}$ D. J. Lockwood, G. Yu, and N. L. Rowell, Solid State Commun. 136, 404 (2005) 